\title{
Detection of the multidrug resistance marker P-glycoprotein by immunohistochemistry in malignant lung tumours
}

\author{
Trevor W Beer, David C Rowlands, John Crocker
}

\begin{abstract}
Background - The multidrug resistance marker P-glycoprotein (P-gp) was studied immunohistochemically in 78 primary malignant lung tumours. $P$-gp is a $170 \mathrm{kD}$ transmembrane ATP dependent drug efflux pump which has been shown to be important in the resistance of some tumours to chemotherapy. Certain normal tissues express $\mathbf{P}$-gp and tumours derived from these tissues are often insensitive to cytotoxic agents, showing raised P-gp levels innately or following chemotherapy or radiotherapy.
\end{abstract}

Methods - Samples from 78 patients undergoing surgery for primary malignant lung tumours were snap frozen and stained immunohistochemically using the monoclonal antibody C219 which reacts with a P-gp epitope. None of the study group had received chemotherapy or radiotherapy before surgery was performed.

Results - Twenty seven of the 78 lung tumours (34.6\%) showed immunohistochemically detectable levels of P-gp which varied with tumour type; 17 of 54 squamous cell carcinomas $(31 \cdot 5 \%)$, seven of 15 adenocarcinomas (46.7\%), and neither of two small cell carcinomas showing positive staining. In six of seven cases normal respiratory epithelium present showed the presence of P-gp.

Conclusions - P-gp is immunohistochemically detectable in frozen tissue from a proportion of malignant lung tumours before exposure to radiotherapy or drugs associated with multidrug resistance. It may have a role in tumour resistance to cytotoxic drugs, but further clinical studies will be required to evaluate any correlation between $\mathbf{P}$-gp levels and response to treatment.

(Thorax 1996;51:526-529)

Keywords: multidrug resistance, P-glycoprotein, lung carcinoma.

Cytotoxic drug resistance is a major problem in cancer chemotherapy. The resistance of neoplastic cells to cytotoxic agents may be innate or acquired and occurs by a number of mechanisms, one of which is associated with the presence of a $170 \mathrm{kD}$ transmembrane protein, P-glycoprotein (P-gp). ${ }^{1}$ This is a product of the multidrug resistance gene $m d r 1$, which acts as an ATP dependent drug efflux pump, reducing intracellular drug concentrations and thereby producing resistance to a large number of structurally unrelated cytotoxic agents. ${ }^{23}$ These include vinca alkaloids, anthracyclines, and epipodophyllotoxins. P-gp has also been observed in drug resistant strains of the malaria parasite Plasmodium falciparum. ${ }^{4}$

Certain normal human tissues have plasma membrane P-gp, with highest levels being observed typically in tissues with an excretory or secretory function such as colonic epithelium, adrenal, kidney, and liver tissue. ${ }^{5}$ Interestingly, tumours derived from these tissues are often insensitive to cytotoxic agents.

In vitro and in vivo studies have identified increased $m d r 1$ gene expression and its product P-gp in several human tumours and cell lines. ${ }^{56}$ Some workers have reported a correlation between innate and acquired multidrug resistance and P-gp expression, suggesting that its presence may be an indicator of resistance to chemotherapy. Inhibition of the pump action of P-gp by verapamil and other agents has been shown to increase cytosensitivity to chemotherapeutic drugs in certain cases. ${ }^{78}$

Lung cancer is one of the commonest human malignancies and carries a poor prognosis. Non-small cell lung carcinomas generally show a poor response to chemotherapy, but the reasons for this are largely unknown. Mechanisms of multidrug resistance probably have a pivotal role in this process. There has recently been some renewal of interest in chemotherapy for non-small cell lung carcinoma ${ }^{9}$ with significant response rates in a number of trials, ${ }^{10}$ especially when used as an adjunct to surgery. ${ }^{112}$ Small cell lung carcinoma often shows a temporary response to chemotherapy, but treatment is largely palliative with little chance of a long term cure.

This study evaluates the expression of P-gp in 78 primary malignant lung tumours unexposed to the potential modulating effects of radiotherapy or chemotherapeutic agents using the monoclonal antibody $\mathrm{C} 219$ which recognises the $m d r 1$ gene product P-gp.

\section{Methods}

Tumour tissue was obtained from 77 patients undergoing lobectomy for primary malignant lung tumours, immediately snap frozen in liquid nitrogen, and stored at $-80^{\circ} \mathrm{C}$. In one patient material was obtained during mediastinoscopy and similarly treated. None of the 
Expression of P-glycoprotein in various types of lung tumours

\begin{tabular}{lllc}
\hline Tumour type & $\begin{array}{l}\text { Number } \\
\text { of }\end{array}$ & \multicolumn{2}{c}{ P-glycoprotein expression } \\
\cline { 2 - 4 } cases & Positive & Negative \\
\hline Squamous carcinoma & 54 & 17 & 37 \\
(all grades) & 7 & 2 & 5 \\
$\quad$ Well differentiated & 30 & 7 & 23 \\
$\quad$ Moderately differentiated & 17 & 8 & 9 \\
Poorly differentiated & 15 & 7 & 8 \\
Adenocarcinoma & 1 & 1 & 0 \\
Adenosquamous carcinoma & 2 & 0 & 2 \\
Small cell carcinoma & 1 & 0 & 1 \\
Atypical carcinoid & 1 & 0 & 1 \\
Carcinoid & 1 & 0 & 1 \\
Large cell anaplastic carcinoma & 1 & 0 & 1 \\
Malignant peripheral nerve sheath tumour & 1 & $1 *$ & 0 \\
Carcinosarcoma & 1 & 1 & 0 \\
Malignant fibrous histiocytoma & 78 & 27 & 51 \\
Total & & & \\
\hline
\end{tabular}

* Staining was confined to the carcinomatous elements.

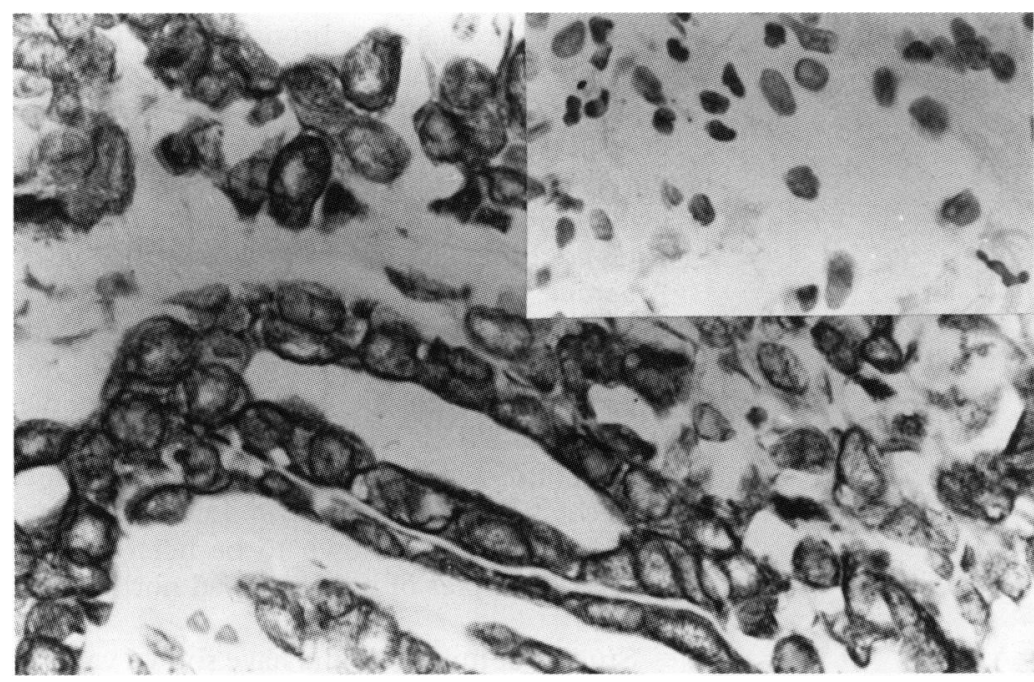

Figure 1 Membranous and cytoplasmic P-gp immunostaining in a primary lung adenocarcinoma. Inset: negative control using non-immune IgG. Original magnification $\times 400$, reduced to $74 \%$ in origination.

patients had received prior chemotherapy or radiotherapy. The patients ranged in age from 40 to 83 years, with 60 being men. The tumours were typed on haematoxylin and eosin stained sections with the use of additional stains and immunohistochemistry where relevant, and classified according to the World Health Organisation histological typing. ${ }^{13}$

Cryostat sections were cut at $4 \mu \mathrm{m}$ with serial sections stained in each case with haematoxylin and eosin and by immunohistochemistry for Pgp using P-glycoCHEK C219 (C219) supplied by Centocor, High Wycombe, UK. C219 is a murine monoclonal antibody (subclass $\operatorname{IgG}_{2 x}$ ) which reacts with a well conserved P-gp epitope. ${ }^{1}$ Immunohistochemical staining was performed using the alkaline phosphatase antialkaline phosphatase (APAAP) method in a moist chamber at room temperature. Slides were incubated for 10 minutes in normal rabbit serum at a 1:50 dilution followed by application of C219 at a 1:20 dilution. The primary antiserum was incubated on the sections overnight. An APAAP detection system was used with the rabbit antimouse immunoglobulins (Z259, Dako) and APAAP complex (Z651, Dako) used at dilutions of $1: 50$ and 1:100, respectively. Two cycles of incubation with the secondary antibody and APAAP complexes were per- formed with appropriate washes between each stage. All secondary antibodies were incubated on the sections for 30 minutes. Sections were then incubated for 20 minutes in the chromogen solution which consisted of $50 \mathrm{mg}$ levamisole (L9756, Sigma), $25 \mathrm{mg}$ naphthol-ASMX-phosphate (N4875, Sigma) in $1 \mathrm{ml} \mathrm{di}-$ methylformamide, and $50 \mathrm{mg}$ fast red TR salt (F2768, Sigma) in $50 \mathrm{ml} 0.1 \mathrm{M}$ Tris buffer, $\mathrm{pH}$ $8 \cdot 2$. Sections were counterstained in Mayer's haematoxylin.

Negative controls were performed by substitution of C219 with a non-immune, isotype matched monoclonal antibody. Commercially supplied positive and negative p-glycoCHEK control slides (Centocor, UK) containing cells from human leukaemia cell lines were also used.

\section{Results}

The presence of P-gp was demonstrated in a proportion of the lung tumours by a red reaction product, variably at the cell membrane, in the cytoplasm, or both (table). A positive reaction was deemed to have occurred when intense staining of $10 \%$ or more of the tumour cells was seen with no staining of the corresponding negative control (fig 1). Overall, 27 of 78 lung tumours $(34.6 \%)$ had immunohistochemically detectable levels of P-gp. This included 17 of $54(31.5 \%)$ squamous cell carcinomas and seven of $15(46.7 \%)$ adenocarcinomas. Within the group of squamous cell carcinomas positive staining was more frequently seen in poorly differentiated tumours than in moderately or well differentiated carcinomas.

The single adenosquamous carcinoma in the group expressed $\mathrm{P}$-gp, but no staining was seen in either of the two small cell carcinomas.

Staining intensity varied both within individual tumours and between tumours, with only parts of some cases demonstrating Pgp. In one poorly differentiated squamous cell carcinoma staining was confined to the invasion front of the tumour (fig 2).

Normal bronchial or bronchiolar epithelium was included with seven tumour samples and in six cases this showed the presence of P-gp. Three of the cases with P-gp expressed in normal constituents also showed P-gp in the adjacent tumour. The staining in normal respiratory epithelium tended to be sited at the plasma membrane or, in some cases, in the cytoplasm towards the luminal aspect of the cells (fig 3).

Of the remaining six miscellaneous tumours, four were negative for P-gp. The single carcinosarcoma available for study showed positive P-gp staining in the carcinomatous elements, but staining was absent in the sarcomatous areas. The malignant fibrous histiocytoma showed diffuse positivity throughout the tumour.

\section{Discussion}

$\mathrm{P}$-gp is important in the resistance of some tumours to cytotoxic chemotherapy and its 


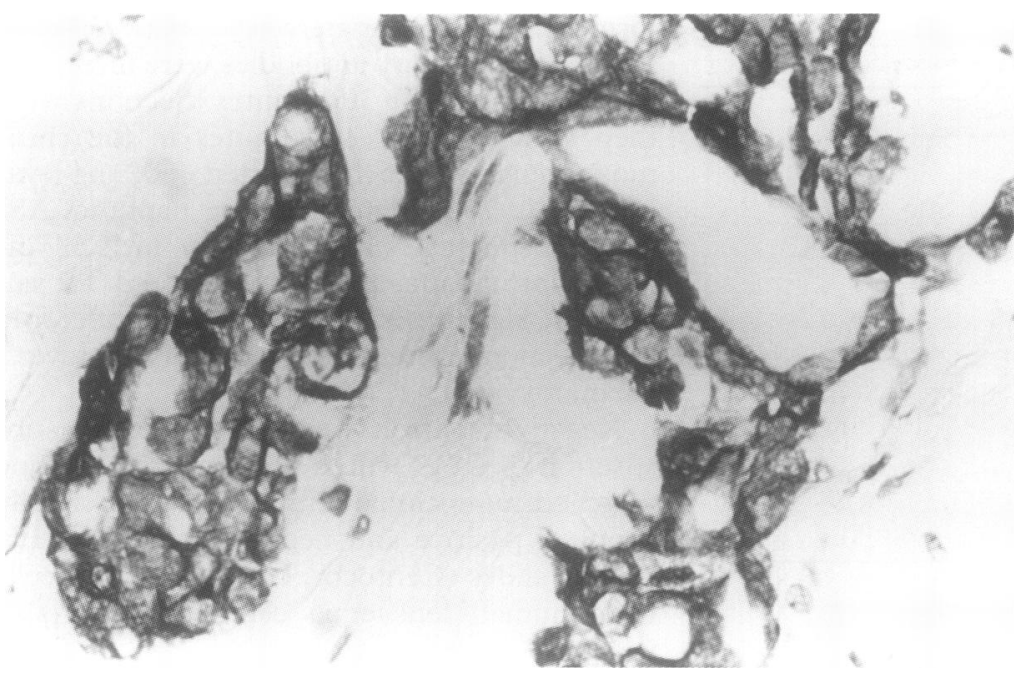

Figure 2 Strong immunostaining for P-gp at the invasion front of a poorly differentiated squamous cell carcinoma. Elsewhere tumour cells were negative in this case. Original magnification $\times 400$, reduced to $74 \%$ in origination.

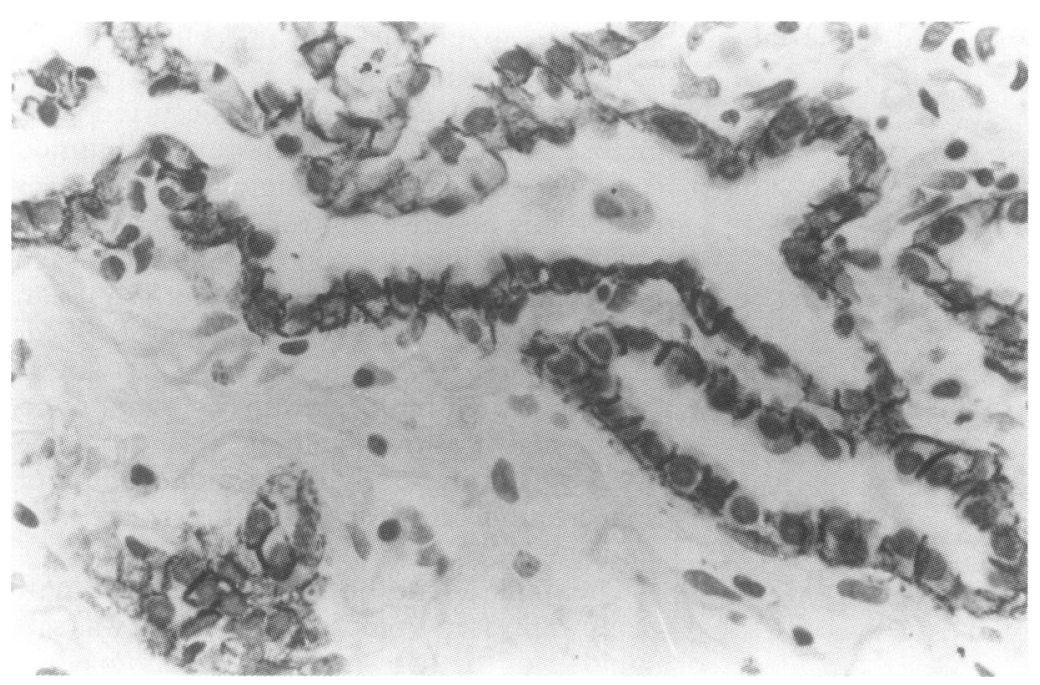

Figure 3 Non-neoplastic bronchiolar epithelium showing strong predominantly membranous $P$-gp expression immunohistochemically. Original magnification $\times 250$, reduced to $74 \%$ in origination.

expression is associated with multidrug resistance. It may be demonstrated in some normal tissues, innately by tumours or following chemotherapy or radiotherapy. Some of the cytogenetic events involved in the acquisition of the MDR phenotype are beginning to be understood, ${ }^{14}$ and modulation of P-gp by adjuvant agents can reverse multidrug resistance, at least temporarily. ${ }^{15}$

This study shows that P-gp can be detected immunohistochemically with the monoclonal antibody C219 in primary malignant lung tumours unexposed to the potential modulating effects of radiotherapy or chemotherapy. More than one third of the tumours expressed Pgp, and amongst the group of squamous cell carcinomas P-gp was more frequently seen in the poorly differentiated tumours than in their better differentiated counterparts. Almost half of the adenocarcinomas revealed evidence of P-gp.

In our experience it is necessary to use cryostat sections of snap frozen material to obtain satisfactory staining; results with formalin fixed paraffin embedded material are unreliable (unpublished observations).

Only tumour cells at the invasion front in one of the poorly differentiated squamous cell carcinomas expressed P-gp, a distribution which has also been observed in a previous study using $\mathrm{C} 219$ by Weinstein et al. ${ }^{5}$ This staining pattern led the authors to suggest that $\mathrm{P}$-gp expression may enhance the invasive potential of tumour cells. It is not clear, however, whether this truly represents increased expression of $\mathrm{P}$-gp, or whether it is merely a reflection of variable immunoreactivity within the tissue. In view of what is known about $\mathrm{P}$-gp at the molecular and functional level, it is not immediately apparent how P-gp might enhance the invasive potential of the tumour cells.

Normal bronchial or bronchiolar epithelium was present in only a small number of the frozen tissue samples, but in most of these cases it showed stainable levels of P-gp. It is of note that the adjacent tumour also showed evidence of P-gp in three cases, but no tumour P-gp could be identified in three further cases. A similar staining pattern in normal tissue has been recorded, ${ }^{5}$ although other workers claim that the normal respiratory system does not express $\mathrm{P}$-gp with the monoclonal antibodies C219 and MRK16 (both directed against P-gp epitopes) on frozen section immunohistochemical examination. ${ }^{16}$ Levels of $m d r 1$ mRNA have been shown to be heterogenous amongst samples of homogenised normal lung tissue. $^{17}$

Studies of lung tumours have shown variable changes in $m d r$ gene expression. Lai et $a l^{18}$ found no evidence of $m d r 1$ gene overexpression, although P-gp mRNA was weakly expressed in 14 of 24 lung tumours, and no increase in P-gp mRNA was found by Northern blotting in a human large cell lung carcinoma line by Reeve et al. ${ }^{19} \mathrm{P}$-gp has been more extensively studied by immunohistochemistry, but again results have been variable. It is well established in the literature and in clinical practice that small cell lung carcinomas may respond to chemotherapy and, interestingly, our two cases did not demonstrate P-gp. Similarly, no staining in four small cell carcinomas was seen using C219 and MRK16, ${ }^{6}$ nor in seven small cell carcinoma cell lines studied by Milroy et $a l^{20}$ even though three had had prior chemotherapy. Four of 33 small cell carcinomas studied by Segawa et $a l^{21}$ expressed P-gp immunohistochemically before chemotherapy, and in seven cases of tumour recurrences after chemotherapy.

One study of non-small cell lung carcinoma ${ }^{22}$ has reported significantly greater P-gp staining in tumours from smokers than from nonsmokers, with $58 \%$ and $9 \%$, respectively, expressing P-gp. They also noted a correlation between smoking and tumour resistance to doxorubicin in vitro in the patients with epidermoid lung carcinoma.

Changes in P-gp staining in lung ${ }^{21}$ and other tumours ${ }^{23-25}$ have been reported following chemotherapy and radiotherapy, ${ }^{26}$ with studies demonstrating a correlation between P-gp and 
resistance to chemotherapy in vitro. ${ }^{222728}$ None of the patients in our study had further samples of tissue taken after exposure to chemotherapy so evaluation of any effect upon P-gp expression cannot be established here.

Because of the implications of P-gp in conferring the multidrug resistance phenotype, a number of workers have attempted to modulate the function of P-gp with inhibitors such as verapamil. ${ }^{371529}$ Encouragingly, studies in vivo and in vitro have shown that in some cases previously resistant tumours have become responsive to chemotherapy - for example, in patients with lymphoma ${ }^{79}$ and in renal carcinoma cell lines. ${ }^{30}$ Selective reversal of vinblastine multidrug resistance-related resistance has also been reported in vitro with antioestrogens. ${ }^{31}$

In conclusion, this study indicates that $\mathrm{P}$-gp can be detected immunohistochemically in a proportion of primary malignant lung tumours and normal lung tissue. The expression of identifiable levels of P-gp before exposure to radiotherapy or drugs associated with multidrug resistance is of clinical relevance. Other researchers have shown that P-gp may have a role in the innate resistance of many lung tumours to chemotherapy. Clinical studies will be required to evaluate any correlation between P-gp and response to treatment. Ultimately, identification of the multidrug resistance phenotype may be of value in avoiding unnecessary chemotherapy in lung tumours which might be predicted to be refractory to treatment. It may also indicate the need for additional agents to block the action of P-gp. Further research is warranted to investigate the predictive value of P-gp as a marker of clinical resistance to chemotherapy.

This research was supported by a grant from the West Midlands Regional Health Authority.

1 Kartner N, Everden-Porelle D, Bradley G, Ling V. Detection of P-glycoprotein in multidrug-resistant cell lines by monoclonal antibodies. Nature 1985;316:820-3.

2 Kartner N, Ling V. Multidrug resistance in cancer. Sci Am 1989;260:44-51.

3 Morrow CS, Cowan KH. Mechanisms and clinical significance of multidrug resistance. Oncology 1988;2:55-68.

4 Krogstad DJ, Gluzman IY, Kyle DE, Oduola AM, Martin Krogstad DJ, Gluzman IY, Kyle DE, Oduola AM, Martin
SK, Milhors WK, et al. Efflux of chloroquine from PlasSK, Milhors WK, et al. Efflux of chloroquine from Plasmodium falciparum: mechanism

5 Weinstein RS, Kuszak JR, Kluskens LF, Coon JS. P-glycoproteins in pathology: the MDR gene family in humans Hum Pathol 1990;21:34-48.

6 Schlaifer D, Laurent G, Chittal S, Tsuruo T, Soues S, Miller $\mathrm{C}$, et al. Immunohistochemical detection of multidrug resistance associated P-glycoprotein in tumour and
stromal cells of human cancers. Br $f$ Cancer 1990;62: 177-82.

7 Miller TP, Grogan TM, Dalton WS, Spier CM, Scheper RJ, Salmon SE. P-glycoprotein expression in malignant lymphoma and reversal of clinical drug resistance with lymphoma and reversal of clinical drug resistance with
chemotherapy plus high-dose verapamil. f Clin Oncol chemotherapy

8 Dalton WS, Grogan TM, Meltzer PS, Scheper RJ, Durie BG, Taylor CW, et al. Drug resistance in multiple myeloma and non-Hodgkin's lymphoma: detection of P-glyco- protein and potential circumvention by addition of verapamil to chemotherapy. $\mathcal{f}$ Clin Oncol 1989;7:415-24

Smith IE. Palliative chemotherapy for advanced non-small cell lung cancer. BMF 1994;308:429-30.

10 Ginsberg RJ, Gris MG, Armstrong JG. Cancer of the lung: non-small cell lung cancer. In: De Vita DT Jr, Hellman S, Rosenberg SA, eds. Cancer: principles and practice of oncology. 4th edn. Philadelphia: JB Lippincott, 1993:673723.

11 Gralla RJ, Kris MG, Martini N. Pre-operative chemotherapy in non-small cell lung cancer in patients with clinically apparent mediastinal node involvement (stage IIIA) with MVP chemotherapy (mitomycin + vinca alkaloid + cisMVP chemotherapy (mitomycin + vinca alkaloid
platin). Chest 1989;96(Suppl 2):1185 (abstract).

12 Burkes R, Ginsberg R, Shepherd F, Blackstein M, Goldberg M, Waters P, et al. Neo-adjuvant trial with MVP (mito$\mathrm{M}$, Waters $\mathrm{P}$, et al. Neo-adjuvant trial with MVP (mito-
mycin-c + vindesine + cisplatin) chemotherapy for stage mycin-c + vindesine + cisplatin) chemotherapy for stage
III unresectable non-small cell lung cancer. Proc Am Soc Clin Oncol 1989;8:221 (abstract).

13 World Health Organisation, 1981 Histological typing of lung tumours. International histological classification of tumours. No. 1. 2nd edn. Geneva: WHO, 1981

14 Nieuwint AW, Baas F, Wiegant J, Joenje H. Cytogenetic alterations associated with P-glycoprotein- and non-Pglycoprotein-mediated multidrug resistance in SW-1573 human lung tumour cell lines. Cancer Res 1992;52:436171.

15 Raderer $M$ and Scheithauer W. Clinical trials of agents that reverse multidrug resistance. A literature review. Cancer 1993;72:3553-63.

16 Pileri SA, Sabattini E, Falini B, Tazzari PL, Gherlinzoni F, Michieli P, et al. Immunohistochemical detection of the multidrug transporter protein P170 in human normal multidrug transporter protein P170 in human normal 19:131-40.

17 Fojo AT, Ueda K, Slamon DJ, Poplack DG, Gottesman MM, Pastan I. Expression of a multidrug resistance gene in human tumours and tissues. Proc Natl Acad Sci 1987; 84:265-9.

18 Lai SL, Goldstein LJ, Gottesman MM, Pastan I, Tsai CM, Johnson BE. MDR1 gene expression in lung carcinoma. $\mathcal{F}$ Natl Cancer Inst 1989;81:1144-50.

19 Reeve JG, Rabbitts PH, Twentyman PR. Non P-glycoprotein mediated multidrug resistance with reduced epidermal growth factor receptor expression in a human large cell lung cancer cell line. Br 7 Cancer 1990;61:851-5.

20 Milroy R, Plumb JA, Batstone P, Maclay A, Wishart GC, Hay FG, et al. Lack of expression of P-glycoprotein in seven small cell lung cancer cell lines established both from untreated and from treated patients. Anticancer Res from untreated and

21 Segawa Y, Ohnoshi T, Hiraki S, Ueoka H, Kiura K, Kamei H, et al. Immunohistochemical detection of P-glycoprotein $\mathrm{H}$, et al. Immunohistochemical detection of $\mathrm{P}$-glycoprotein and carcinoembryonic antigen in small cell lung cancer:
with reference to predictability of response to chemowith reference to predictability of response
therapy. Acta Med Okayama 1993;47:181-9.

22 Volm M, Mattern J, Samsel B. Overexpression of P-glycoprotein and glutathione-S-transferase $\pi$ in resistant non small cell lung carcinoma of smokers. Br f Cancer 1991; 64:700-4.

23 Bashir I, Sikora K, Foster CS. Multidrug resistance in prostate cancer of distinct metastatic phenotypes. $\mathcal{F}$ Pathol 1992;167(Suppl 95-172):147(abstract).

24 Rutledge ML, Robey-Cafferty SS, Silva EG, Bruner JM. Monoclonal antibody (C219) detection of the MDR protein (P-glycoprotein) in routinely processed tissues: a study of 368 - 301 .

25 Schneider J, Bak M, Efferth T, Kaufman M, Mattern J, Volm M. P-glycoprotein expression in treated and unVolm M. P-glycoprotein expression in treated and un-

treated human breast cancer. Br $\mathcal{F}$ Cancer 1989;60:815-8.
26 Mattern J, Efferth T, Volm M. Overexpression of P-glycoprotein in human lung carcinoma xenografts after fracprotein in human lung carcinoma xenografts after frac-
tionated irradiation in vivo. Radiat Res 1991;127:335-8.

27 Volm M, Mattern J, Samsel B. Relationship of inherent resistance to doxorubicin, proliferative activity and expression of P-glycoprotein 170, and glutatione S-transferase $\pi$ in human lung tumours. Cancer 1992;70:764-9.

28 Volm M, Efferth T, Bak M, Ho AD, Mattern J. Detection of the multidrug resistance phenotype in human tumours by monoclonal antibodies and the streptavidin-biotinylated phycoerythrin complex method. Eur $\mathcal{f}$ Clin Oncol 1989;25:743-9.

29 Gottesman MM, Pastan I. Clinical trials of agents that reverse multidrug resistance. F Clin Oncol 1989;7:409-11.

30 Fojo AT, Shen DW, Mickley LA, Paston I, Gottesman MM. Intrinsic drug resistance in human kidney cancer is associated with expression of a human multidrug resistance associated with expression of a huma

31 Kirk J, Houlbrook S, Stuart NS, Stratford IJ, Harris AL Selective reversal of vinblastine resistance in multidrugmetabolites. Eur $\mathcal{F}$ Cancer 1993;29A:1152-7. 